\title{
Interaction of Hemoglobin with Binuclearcationic Tetranitrosyl Iron Complex with Penicillamine. Cations Binding Sites
}

\author{
Lidia Syrtsova, Natalia Sanina, Boris Psikha, Ildar Tukhvatullin, Natal'ja Shkondina, \\ Olesia Pokidova, Alexander Kotelnikov \\ Institute of Problems of Chemical Physics of the Russian Academy of Sciences, Moscow Region, \\ Russian Federation \\ Email: syrtsova@icp.ac.ru
}

Received 7 December 2014; accepted 22 April 2015; published 28 April 2015

Copyright (C) 2015 by authors and Scientific Research Publishing Inc.

This work is licensed under the Creative Commons Attribution International License (CC BY). http://creativecommons.org/licenses/by/4.0/

\section{(c) (i) Open Access}

\begin{abstract}
In this paper, the kinetics of the interaction of the nitrosyl iron complex with the ligands penicillamine $\left[\mathrm{Fe}_{2}\left(\mathrm{SC}_{5} \mathrm{H}_{11} \mathrm{NO}_{2}\right)_{2}\left(\mathrm{NO}_{4}\right] \mathrm{SO}_{4} \cdot 5 \mathrm{H}_{2} \mathrm{O}(I)\right.$ with deoxyhemoglobin (Hb) was studied. The kinetic modeling method defined the number of binding (I) molecules and equilibrium constant of the coupling reaction of $(I)$ with $\mathrm{Hb}\left(K_{s}\right)$. At equimolar concentrations of $(I)$ and $\mathrm{Hb}\left(2 \times 10^{-5} \mathrm{M}\right)$, the $\mathrm{Hb}$ molecule binds only one $(I)$ with $K_{s}$ equal to $4.3 \times 10^{7} \mathrm{M}^{-1}$. When increasing the $(I)$ concentration, the number of binding sites of $\mathrm{Hb}$ increases and $K_{s}$ decreases. These results are analyzed in accordance with the data on the existence of cations binding sites in $\mathrm{Hb}$.
\end{abstract}

Keywords

Biomedicine, Iron-Sulfur Cluster, Ligand Binding, Heme, Nitric Oxide

\section{Introduction}

In the last ten years, it has been well established that nitric oxide, NO, having a wide spectrum of biological activities and the ability to affect various body systems [1] [2], is actively involved in the process of carcinogenesis [3]. Depending on the chemical characteristics and the local concentration in vivo, NO may act on different biotargets to stimulate the tumor generation process or vice versa, exercising its inhibition [4]-[6]. In this regard, the development of experimental approaches to treatment of neoplastic diseases that are based on NO-therapy 
requires fundamental study correlations, investigating the "Structure-Activity" of exogenous compounds generating NO in physiological solutions, in order to establish the molecular and genetic mechanisms of their action on target mammalian cells and for the synthesis of compounds with improved properties (low toxicity, greater bioavailability, etc.). Biomimetics of nitrosyl cell intermediates, in particular, synthetic models of the active centers of nitrosyl iron-sulfur proteins, are promising compounds for the treatment of neoplastic diseases [7]. We have previously shown, for the first time, that the anionic and neutral nitrosyl iron complexes (NICs), in the absence of additional activation, decompose with release of $\mathrm{NO}$ in protic media containing $\mathrm{Hb}$ [8] [9], and that the reaction rate constants depend on the molecular structure of the complexes. It was found that the NICs nitrosylated $\mathrm{Hb}$, interacting with the heme at the 6th free coordination site. The resulting complex, $\mathrm{HbNO}$, is a depot of NO. It not only provides a storage form of NO (since the lifetime of free NO in the cell is seconds), but also determines the prolonged action of the NICs as donors of NO. It was also found that NIC nitrosylated not only $\mathrm{Hb}$ but also ferri- and ferrocytochrome [10]. It is known [11] that there is a center in $\mathrm{Hb}$ for binding of anions formed by positively charged functional amino acid residues that can bind, for example, diphosphoglycerate (DPG). As a result of allosteric binding, DPG affects $\mathrm{Hb}$ affinity for $\mathrm{O}_{2}$. Recently, we have identified the binding sites of cations in $\mathrm{Hb}$ [12]. It was found that a cationic NIC (Figure 1) with cysteamine ligands (II) $\left[\mathrm{Fe}_{2}\left(\mathrm{~S}_{(}\left(\mathrm{CH}_{2}\right)_{2} \mathrm{NH}_{3}\right)_{2}(\mathrm{NO})_{4}\right] \mathrm{SO}_{4} \cdot 2.5 \mathrm{H}_{2} \mathrm{O}(\mathrm{CCDC} 663194)$, was a promising anticancer NO-donor agent, apoptosis inducer in human tumor cells [13], bound with two negatively charged cavities on the Hb surface. These issues are important for the metabolism of cationic NICs and also for investigating the first discovered sites of cation binding in such a physiologically relevant protein as $\mathrm{Hb}$. So, we determined the goal of this work to be the investigation of the binding of $\mathrm{Hb}$ with other cationic complex, (I) (Figure 1) with larger size than (II), in order to reliably verify the existence of cations binding sites in $\mathrm{Hb}$. According to the $\mathrm{X}$-ray diffraction data, the complex (I) contains two protonated $\mathrm{NH}_{3}$-groups in the penicillamine ligands: $\left[\mathrm{Fe}_{2}\left(\mathrm{SC}_{5} \mathrm{H}_{11} \mathrm{NO}_{2}\right)_{2}(\mathrm{NO})_{4}\right] \mathrm{SO}_{4} \cdot 5 \mathrm{H}_{2} \mathrm{O}$ (CCDC 680286).

\section{Experimental}

\subsection{Materials}

We used bovine $\mathrm{Hb}$ (Serva, Germany), $\mathrm{Na}_{2} \mathrm{HPO}_{4} \cdot 6 \mathrm{H}_{2} \mathrm{O}$ and $\mathrm{NaH}_{2} \mathrm{PO}_{4} \cdot \mathrm{H}_{2} \mathrm{O}$ (MP Biomedicals, Germany). The water was purified by distillation in a Bi/Duplex distiller (Germany). (II) was synthesized using the known method [14]. Synthesis of (I) is described in [15]. It has been obtained by reaction of dissolved in water ferrous

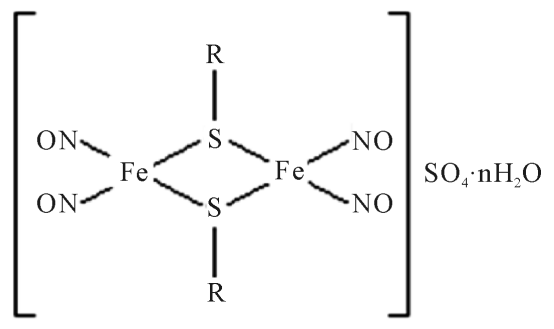<smiles>CC(C)(C)C([NH3+])C(=O)O</smiles>

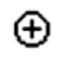

(II) $\mathrm{R}_{2}=\mathrm{NH}_{3}-\mathrm{CH}_{2}-\mathrm{CH}_{2}-\mathrm{n}=2.5$

Figure 1. Chemical structures of the tetranitrosyl

iron complexes (I) and (II) [14] [15]. 
sulphate (II) with an aqueous solution of D-penicillamine in the molar ratio 1:3. The reaction was performed using standard vacuum line and Schlenk technology under argon. Previously, oxygen has been removed from the water by triple freezing and vacuum pumping. To the dry mixture, containing $0.42 \mathrm{~g}(1.5 \mathrm{mmol})$ of $\mathrm{FeSO}_{4} \cdot 7 \mathrm{H}_{2} \mathrm{O}$ and $0.68 \mathrm{~g}(4.5 \mathrm{mmol}) \mathrm{D}$-penicillamine poured $10 \mathrm{ml}$ water, prepared as described above, and nitric oxide have been passed through the resulting deep purple solution at room temperature. The fine red needles have been appeared on the walls of the reaction vessel after 10 - 12 min, gradually filling the entire volume of the solution. The mixture was kept 3 days at $6^{\circ} \mathrm{C}-8^{\circ} \mathrm{C}$, filtered and dried in vacuum under argon. The filtered product is stable in the solid phase in the air for a long time (months). Yield is $198 \mathrm{mg}$ (20\%). Elemental analysis of the polycrystalline powders obtained was performed at the Analytical Center of the Institute of Problems of Chemical Physics of the Russian Academy of Sciences. For (I): $\mathrm{Fe}_{2} \mathrm{~S}_{3} \mathrm{~N}_{6} \mathrm{C}_{10} \mathrm{H}_{32} \mathrm{O}_{17}$. Found \%: Fe, 15.62; S, 13.34; N, 11.89; C, 16.80, H, 4.62. Calculated, \%: Fe, 15.64; S, 13.42; N, 11.72; C, 16.76, O, 37.99; H, 4.47; IR: $v / \mathrm{cm}^{-1}=1771$ (s, NO); 1723 (s, NO).

\subsection{Operation Technique in Inert Gas Atmosphere}

Operation technique in inert gas atmosphere has been described earlier [8].

\subsection{Preparation of $\mathrm{Hb}$ Solution}

A homogeneous solution of bovine $\mathrm{Hb}$ was prepared from commercial $\mathrm{Hb}$ (a mixture of oxygenated hemoglobin $\left(\mathrm{HbO}_{2}\right)$ and methemoglobin according to a known procedure [9].

\subsection{Kinetics of Hb Reaction with the Complex (I)}

To a weighed sample of the (I) in a vessel filled with nitrogen, an anaerobic $0.05 \mathrm{M}$ phosphate buffer, $\mathrm{pH} 7.0$, was added so as to prepare a solution of the complex with a concentration of $6 \times 10^{-4} \mathrm{M}$. Then the solution was stirred for 15 min under a nitrogen stream until the complex was completely dissolved. An aliquot (0.1: 0.5; 0.75; $1 \mathrm{ml}$ ) of the solution was drawn under a nitrogen stream and transferred to the anaerobic sample cell and the reference cell (the volume $4 \mathrm{ml}$, the optical path length $1 \mathrm{~cm}$ ) containing an anaerobic phosphate buffer, $\mathrm{pH} 7.0$ in an amount sufficient for obtaining the final (I) concentration $2 \times 10^{-5} ; 10^{-4} ; 1.5 \times 10^{-4}$ and $2 \times 10^{-4} \mathrm{M}$, respectively. Then the phosphate buffer, $\mathrm{pH}$ 7.0, was added to the reference and sample cells in amounts required to make the volume of the reaction solution after the insertion of $\mathrm{Hb}$ into the sample cell equal to $3.0 \mathrm{ml}$. The reaction was initiated by adding an $\mathrm{Hb}$ solution with the initial concentration of $4.5 \times 10^{-4} \mathrm{M}$ into the sample cell. The concentration of $\mathrm{Hb}$ in the sample cell was $(1.94-2.1) \times 10^{-5} \mathrm{M}$. Then the difference absorption spectra were recorded at certain time intervals. The absorption spectra were measured until $\mathrm{Hb}$ was completely transformed into $\mathrm{HbNO}$, i.e., until the spectra stopped to change.

\subsection{Absorption Spectra}

Absorption spectra were recorded at $25^{\circ} \mathrm{C}$ using a Specord M-40 spectrophotometer equipped with an interface for computer-aided registration of spectra and thermostatic cuvette holder. Amount of $\mathrm{Hb}$ and $\mathrm{HbNO}$ was evaluated spectrophotometrically. For this purpose absorption spectra were factored by components using program Mathcad 11 Enterprise Edition as described in the paper [8].

\subsection{For Kinetic Modeling}

We considered the assumed reaction scheme describing the interaction of $(\boldsymbol{I})$ with $\mathrm{Hb}$. The rate constants were determined by the least squares method based on the numerical solution of the corresponding system of differential equations. The concentrations of $\mathrm{NO}$ or the $\mathrm{HbNO}$ were determined after the resolution of the absorption spectra into components (the spectra of $\mathrm{Hb}$ and $\mathrm{HbNO}$ ), and used as experimental data.

\subsection{The Analysis of Hb Surface}

The analysis of Hb surface was performed using the program PyMOL [16]. To view and analyze the surface of $\mathrm{Hb}$, we used X-ray data of bovine Hb [17], retrieved from the database PDB, access code 1HDA (see Ref. [18]). This method allowed us to determine the total electrostatic surface charge. The density of the color depends on 
its magnitude. Dimensions can be determined with an accuracy of $~ 10 \%$.

\section{Results and Discussion}

\subsection{Reaction of ( $I$ ) with $\mathrm{Hb}$}

In the present work we studied the interaction of $(\boldsymbol{I})$ with $\mathrm{Hb}$. All reactions with complex $(\boldsymbol{I})$ were carried out under nitrogen because NO rapidly reacts with $\mathrm{O}_{2}$ to give nitrogen oxides (the rate constant is $2 \times 10^{6} \mathrm{M}^{-2} \cdot \mathrm{s}^{-1}$ ) [19]. $\mathrm{Hb}$ is a trap for NO: the binding rate is close to the diffusion rate [20], the equilibrium constant is $3 \times 10^{10}$ $\mathrm{M}^{-1}$ [21]. Hb gives a characteristic absorption spectrum, which changes in the course of NO binding. Hence, as was reported in [8] [9], the NO release can be followed from the formation of HbNO. Since all sulfur-nitrosyl iron complexes show absorption in the visible region, we recorded the difference absorption spectra of the control and test systems with $\mathrm{Hb}$ containing the complex $(\boldsymbol{I})$ at the same concentrations (see the Experimental section). The changes in the difference absorption spectra with time in the course of the reaction of $\mathrm{Hb}$ with the complex (I) are displayed in Figure 2. We stopped recording the spectra after the latter ceased to change. This was accompanied by a decrease in the absorbance at the maximum at $556 \mathrm{~nm}$ in the absorption spectrum of $\mathrm{Hb}$ and an increase in the absorbance at 545 and $575 \mathrm{~nm}$ suggesting the formation of the HbNO complex. These

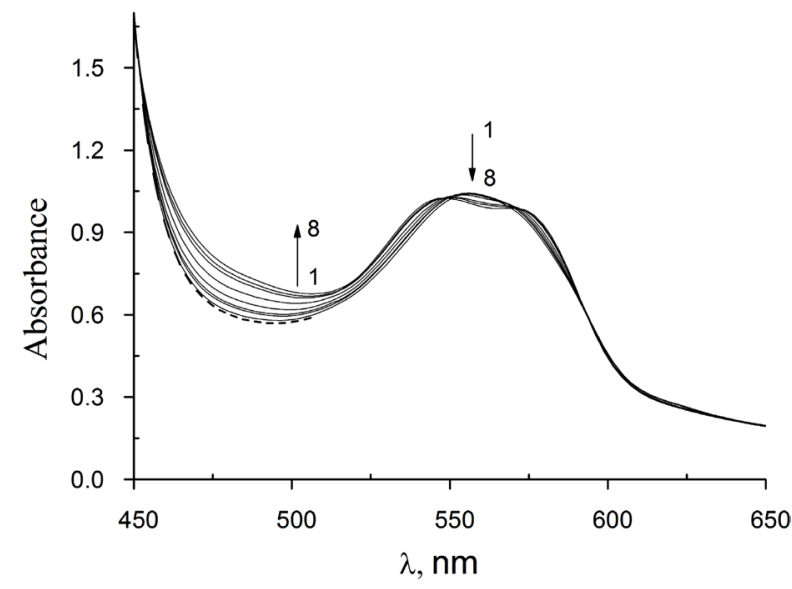

(a)

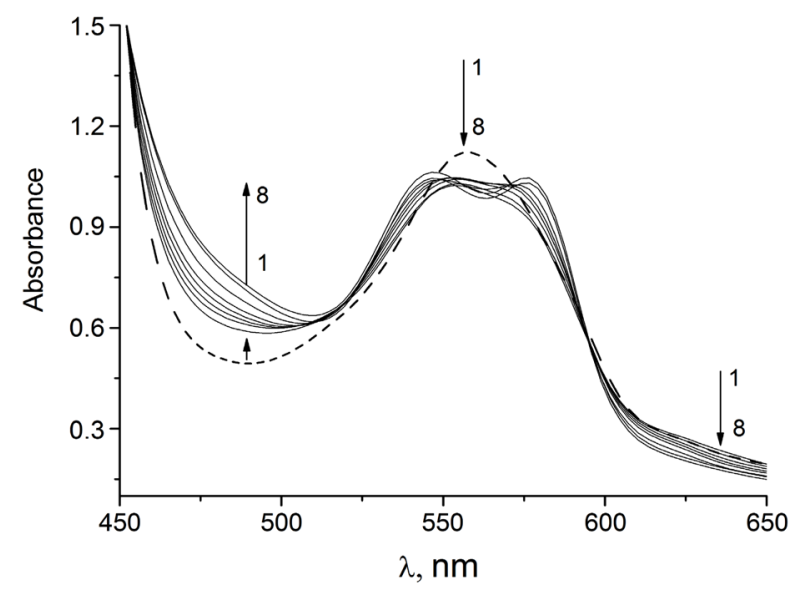

(c)

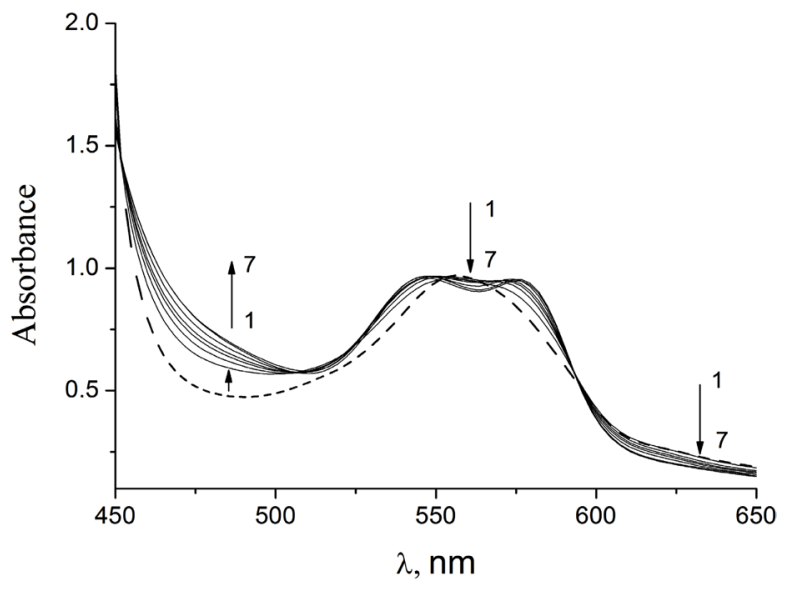

(b)

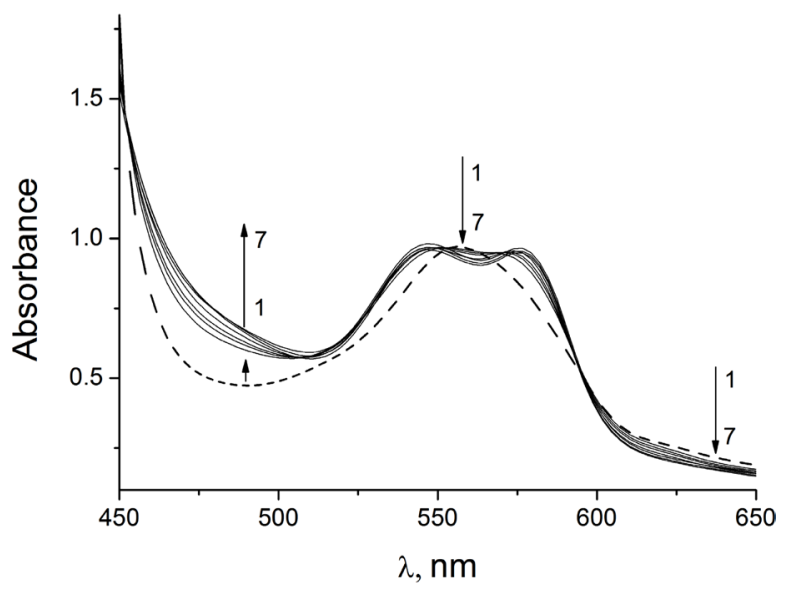

(d)

Figure 2. Kinetics of change of difference spectra at the interaction of (I): $2 \times 10^{-5}$ (a), $10^{-4}$ (b), $1.5 \times 10^{-4}$ (c) $2 \times 10^{-4}$ (d) $\mathrm{M}$ with $\mathrm{Hb} 2 \times 10^{-5}$ (a), $1.96 \times 10^{-5}$ (b) $2.1 \times 10^{-5}$ (c), $1.94 \times 10^{-5}$ (d) M. $\lambda=450-650 \mathrm{~nm}$. Solvent is $0.05 \mathrm{M}$ phosphate buffer, $\mathrm{pH} 7.0$, temperature is $25^{\circ} \mathrm{C}$. Dotted lines are the spectrum of $\mathrm{Hb}$. Spectra $1-8$ were registered at $0.16,0.33,0.5,0.66$, $0.91,1.16,2.16,3.16$ (a), $0.03,0.07,0.1,0.15,0,33,1,2.25,3.16$ (c), spectra $1-7$ were registered at $0.03,0.07,0.12,0.27$, $0.42,0.67,3.83$ (b), and $0.05,0.1,0.15,0.25,1.35,1.83,3.92$ (d) h after start of reaction. Conditions of reaction: $25^{\circ} \mathrm{C}$, solvent is $0.05 \mathrm{M}$ phosphate buffer, $\mathrm{pH}$ 7.0. 
spectra have three isosbestic points at 551, 570, and $595 \mathrm{~nm}$. This is evidence that only $\mathrm{Hb}$ and HbNO contribute to the absorption spectra, as in the case of the reactions of this class of NICs with Hb investigated in our earlier research [8]. We measured the kinetics of the formation of HbNO by recording the accumulation of HbNO and the deconvolution of the absorption spectra with the use of the MathCad program (Figure 3). The rate constants $k$ (Table 1) is somewhat less than the constant rate of NO release from $(I)$, defined by the sensor electrode in $0.05 \mathrm{M}$ phosphate buffer $\mathrm{pH} 7.0$ and a temperature $25^{\circ} \mathrm{C}$ in a nitrogen atmosphere: $k_{1}=(4.6 \pm 0.1) \times 10^{-3} \mathrm{~s}^{-1}$ [22]. In [8] the authors explain why the HbNO formation reaction should "track" the NO released from NIC. We firmly established that $\mathrm{Hb}$ usually stabilizes the NIC and the reaction of NO release in the presence of $\mathrm{Hb}$ is slower than without $\mathrm{Hb}$, as was found in the determination of the reaction rate of NO release from NIC using the sensor electrode [12]. We have determined that sulfur ligands, which are part of the NICs with excess electron density, contribute to the stabilization of complexes in solution [9]. The greater the electron density on the NIC ligand, the more stable it is in the presence of $\mathrm{Hb}$ [23]. This stabilization is due to a known anion-binding center in $\mathrm{Hb}$, located in the cavity between $\mathrm{Hb}$ subunits [11]. Recently, we described the presence of cations binding sites on Hb. In the case of the cationic NIC (II), having thiol ligands cysteamine instead of penicillamines there was significant stabilization of the complex in the presence of $\mathrm{Hb}$. This was attributed to the presence of the cationic sites, negative charge centers, reversible binding (II), and that these centers were visualized [12]. The size of (I) was greater than the size of (II). Thus, using the program PyMOL [16], we found that the size of the (I) dication is $\sim 375 \AA^{3}$, while the size of the (II) dication is equal to $\sim 265 \AA^{3}$ [12].

\subsection{Kinetic Modeling of the Reactions of (I) with $\mathrm{Hb}$}

Consider the reaction of $(\boldsymbol{I})$ with $\mathrm{Hb}$. If $\mathrm{Hb}$ is present in the medium, it seems, due to the large value of the equilibrium constant of $\mathrm{Hb}+\mathrm{NO} \rightleftharpoons \mathrm{HbNO}$, equal to $3 \times 10^{10} \mathrm{M}^{-1}$ [21], it shifts the equilibrium decomposition reaction of $(\boldsymbol{I})$ towards the formation of $\mathrm{HbNO}$ and, being a depot for NO, carries it to the respective targets.

Table 1. The values of the kinetic parameters $K_{s}$ and $n_{s}$, describing the interaction of the complex (I) with Hb.

\begin{tabular}{ccccc}
\hline No & {$[(\boldsymbol{I})]_{0} \cdot 10^{5}, \mathrm{M}$} & {$[\mathrm{Hb}]_{0} \cdot 10^{5}, \mathrm{M}$} & $n_{\mathrm{s}}$ & $K_{\mathrm{s}} \cdot 10^{-7}, \mathrm{M}^{-1}$ \\
\hline 1 & 2 & 2.0 & 1.0 & 4.3 \\
2 & 10 & 1.96 & 5.0 & 0.80 \\
3 & 15 & 2.10 & 7.0 & 0.71 \\
4 & 20 & 1.94 & 10.2 & 0.64 \\
\hline
\end{tabular}

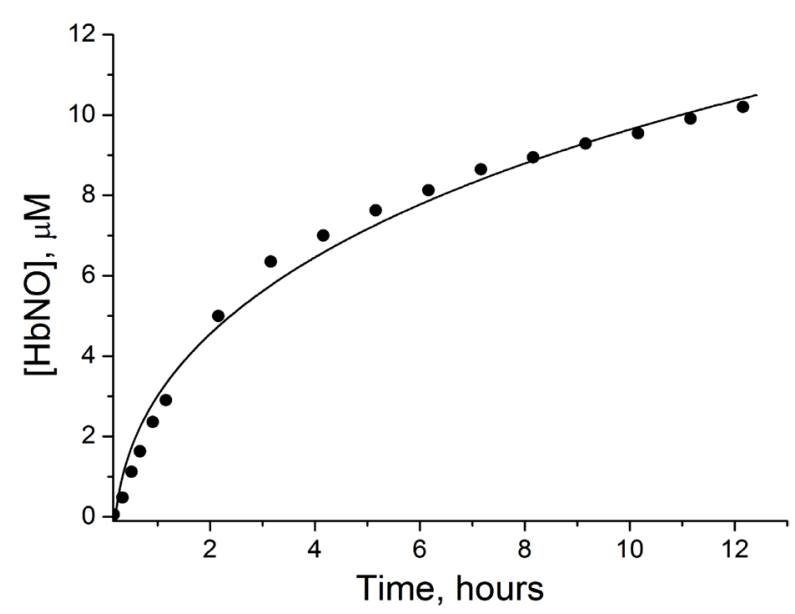

(a)

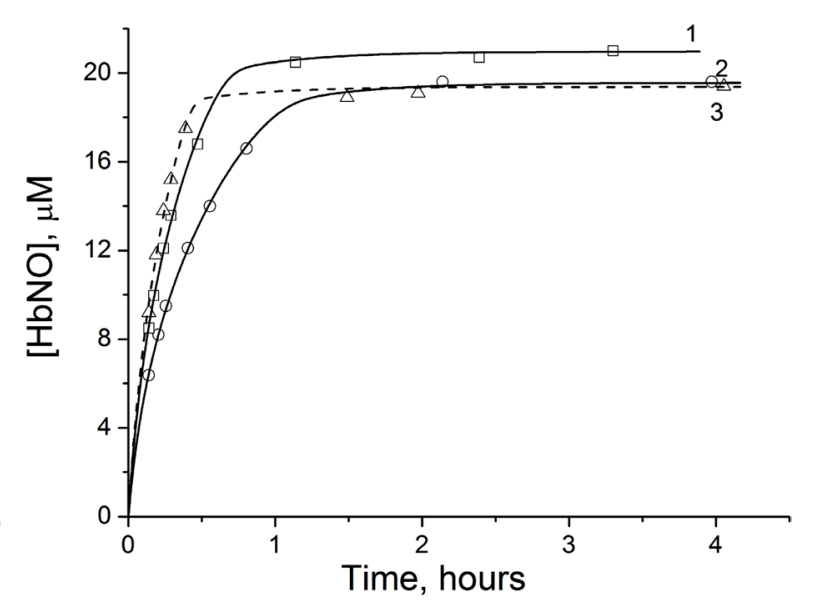

(b)

Figure 3. Kinetics of HbNO formation upon interaction of (I) (a) $2 \times 10^{-5}$ and (b): $10^{-4}$ (2), $1.5 \times 10^{-4}$ (1) and $2 \times 10^{-4}$ (3) M with $\mathrm{Hb}$ : [Hb $]_{0}$ (a) $2.0 \times 10^{5}$, and (b): $1.96 \times 10^{5}$ (1), $2.1 \times 10^{5}(2), 1.94 \times 10^{5}$ (3) M. Points are the experimental data, the lines are calculation on the basis of the reactions of Figure 2. Kinetic curve 2 in (b) is based on data in Figure 2(b); the curve 1, Figure 2; curve 3, Figure 2(d). 
Without the Hb equilibrium decomposition reaction of (I), evidently biased toward (I) decomposition. It is consumed in the reactions of NO, known as the universal controllers necessary for functions of cellular metabolism [1] [2].

In [12], the authors observed a decrease in the processing rate for NO release for cysteamine cationic NIC (II) in the presence of $\mathrm{Hb}$, which was explained by adsorption of the complex by the $\mathrm{Hb}$ molecule, resulting in a substantially reduced capacity of (II) to evolve NO. For (I), a structural analog of (II), the reaction scheme corresponds to a model of the given process:

$$
\begin{gathered}
\text { (I) } \stackrel{\left(k_{1}, k_{-1}\right)}{\rightleftharpoons} \mathrm{P}_{1}+\mathrm{NO} \\
\mathrm{P}_{1} \stackrel{\left(k_{2}, k_{-2}\right)}{\rightleftharpoons} \mathrm{P}_{2}+\mathrm{L} \\
(I) \stackrel{\left(k_{3}\right)}{\rightleftharpoons} \mathrm{P}_{3}+\mathrm{L} \\
(I)+\mathrm{S}_{\mathrm{Hb}} \stackrel{(\mathrm{Ks})}{\rightleftharpoons}(I)-\mathrm{S}_{\mathrm{Hb}} \\
(I)-\mathrm{S}_{\mathrm{Hb}} \stackrel{\left(k_{4}\right)}{\rightleftharpoons} \mathrm{NO} \\
\mathrm{Hb}+\mathrm{NO} \stackrel{\left(k_{5}, k_{-5}\right)}{\rightleftharpoons} \mathrm{HbNO}
\end{gathered}
$$

Here $\mathrm{S}_{\mathrm{Hb}}$ are the active binding site of $(\boldsymbol{I})$ on Hb surface.

In accordance with this scheme, the free molecules of complex (II) evolve NO in solution, with reversible reaction rate constants $k_{1}$ and $k_{-1}$. Decomposition of $(\boldsymbol{I})$ in water is followed by separation of the penicillamine ligand [22] from molecule $(\boldsymbol{I})$ and the product $\mathrm{P}_{1}$, which is obtained after the separation of NO from $(\boldsymbol{I})$, as seen in reactions (2) and (3). Simultaneously, the molecule is $(\boldsymbol{I})$ adsorbed on an $\mathrm{Hb}$ macromolecule. It is assumed that the binding sites of (I) exist on $\mathrm{Hb}$ surface (in a certain amount, $n_{s}$ per $\mathrm{Hb}$ molecule), with which the molecule of complex (I) can reversibly interact with an equilibrium constant, $K_{s}$. In the bound state of the complex, molecules evolve NO with a rate constant of $k_{4}$. The separated NO molecules reversibly interact with the heme iron of $\mathrm{Hb}$ to form the experimentally measured $\mathrm{HbNO}$ product.

He values of rate constants $k_{1}=4.6 \times 10^{-3} \mathrm{~s}^{-1}, k_{-1}=9.7 \times 10^{3} \mathrm{M}^{-1} \cdot \mathrm{s}^{-1}, k_{2}=5.3 \times 10^{-4} \mathrm{~s}^{-1}, k_{-2}=0.1 \mathrm{M}^{-1} \cdot \mathrm{s}^{-1}, k_{3}$ $=6.6 \times 10^{-6} \mathrm{~s}^{-1}$ we determined in paper [22]. The literature contains information on the value of the constant $k_{5}$ $=10^{8} \mathrm{~s}^{-1}$ [19] and the equilibrium constant $K_{5}, k_{5} / k_{-5}$, equal to $3 \times 10^{10} \mathrm{M}^{-1}$ [21]. The unknown parameters are $K_{s}$, $n_{s}$ and $k_{4}$. Analysis of the inverse problem has shown that by available experimental data, these parameters cannot be uniquely determined. Therefore, in a first approximation, we considered the limiting case when NO release by the bound complex $(\boldsymbol{I})-\mathrm{S}_{\mathrm{Hb}}$ is negligible. This regime corresponds to the value of $k_{4} \sim 10^{-8} \mathrm{~s}^{-1}$ [12], as in the case of (II). The problem reduces to the determination with the experimental data [HbNO](t), the equilibrium constant $K_{s}$, and the number of active sites on the surface of the hemoglobin, $n_{s}$.

The corresponding system of equations is as follows:

$$
\begin{gathered}
\frac{\mathrm{d}[(I)]}{\mathrm{d} t}=\left(-k_{1}[(\boldsymbol{I})]+k_{-1}\left[\mathrm{P}_{1}\right][\mathrm{NO}]-k_{3}[(\boldsymbol{I})]\right)-\beta \cdot k_{4}\left[(\boldsymbol{I}) \mathrm{S}_{\mathrm{Hb}}\right] \\
\frac{\mathrm{d}\left[\mathrm{S}_{\mathrm{Hb}}\right]}{\mathrm{d} t}=-(1-\alpha)\left(-k_{1}[(\boldsymbol{I})]+k_{-1}\left[\mathrm{P}_{1}\right][\mathrm{NO}]-k_{3}[(\boldsymbol{I})]\right)-\beta \cdot k_{4}\left[(I) \mathrm{S}_{\mathrm{Hb}}\right] \\
\frac{\mathrm{d}\left[\mathrm{P}_{1}\right]}{\mathrm{d} t}=k_{1}[(\boldsymbol{I})]-k_{-1}\left[\mathrm{P}_{1}\right][\mathrm{NO}]-k_{2}\left[\mathrm{P}_{1}\right]+k_{-2}\left[\mathrm{P}_{2}\right][\mathrm{L}] \\
\frac{\mathrm{d}[\mathrm{NO}]}{\mathrm{d} t}=k_{1}[(\boldsymbol{I})]-k_{-1}\left[\mathrm{P}_{1}\right][\mathrm{NO}]+k_{4}\left[(\boldsymbol{I}) \mathrm{S}_{\mathrm{Hb}}\right]-k_{5}[\mathrm{Hb}][\mathrm{NO}] \\
\frac{\mathrm{d}\left[\mathrm{P}_{2}\right]}{\mathrm{d} t}=k_{2}\left[\mathrm{P}_{1}\right]-k_{-2}\left[\mathrm{P}_{1}\right][\mathrm{L}] \\
\frac{\mathrm{d}[\mathrm{L}]}{\mathrm{d} t}=k_{2}\left[\mathrm{P}_{1}\right]-k_{-2}\left[\mathrm{P}_{2}\right][\mathrm{L}]+k_{3}[(I)]
\end{gathered}
$$




$$
\begin{gathered}
\frac{\mathrm{d}\left[\mathrm{P}_{3}\right]}{\mathrm{d} t}=k_{3}[(I)] \\
\frac{\mathrm{d}[\mathrm{Hb}]}{\mathrm{d} t}=-k_{5}[\mathrm{Hb}][\mathrm{NO}] \\
\frac{\mathrm{d}[\mathrm{HbNO}]}{\mathrm{d} t}=k_{5}[\mathrm{Hb}][\mathrm{NO}] \\
{\left[(I) \mathrm{S}_{\mathrm{Hb}}\right](\mathrm{t})=K_{s}[(I)](\mathrm{t}) \cdot\left[\mathrm{S}_{\mathrm{Hb}}\right](\mathrm{t})}
\end{gathered}
$$

Here $\alpha=\frac{1+K_{S}[(I)]}{1+K_{S}[(I)]+K_{S}\left[\mathrm{~S}_{\mathrm{Hb}}\right]} ; \beta=\frac{1}{1+K_{S}[(I)]+K_{S}\left[\mathrm{~S}_{\mathrm{Hb}}\right]}$.

The initial conditions, taking into account the detailed balance in the reaction (4):

$$
[(I)](0)=\left(-\mathrm{b}+\left(\mathrm{b}^{2}+4 \mathrm{~K}_{\mathrm{s}}[(\boldsymbol{I})]_{0}\right)^{0.5}\right) /\left(2 K_{s}\right),
$$

where

$$
\begin{gathered}
\mathrm{b}=1-K_{s}\left([(I)]_{0}-\left[\mathrm{S}_{\mathrm{Hb}}\right]_{0}\right) ; \\
{\left[\mathrm{S}_{\mathrm{Hb}}\right](0)=[(I)](0)-[(I)]_{0}+\left[\mathrm{S}_{\mathrm{Hb}}\right]_{0} ;} \\
{[\mathrm{Hb}](0)=[\mathrm{Hb}]_{0} ;} \\
{\left[\mathrm{P}_{1}\right](0)=[\mathrm{NO}](0)=\left[\mathrm{P}_{2}\right](0)=[\mathrm{L}](0)=\left[\mathrm{P}_{3}\right](0)=[\mathrm{HbNO}](0)=0 ;}
\end{gathered}
$$

Here $[(\boldsymbol{I})]_{0},[\mathrm{Hb}]_{0},\left[\mathrm{~S}_{\mathrm{Hb}}\right]_{0}=\mathrm{n}_{\mathrm{s}} \cdot[\mathrm{Hb}]_{0}$ are the initial concentrations of the complex $(\boldsymbol{I}), \mathrm{Hb}$, and the active sites on the surface $S_{\mathrm{Hb}}$, respectively.

Unknown kinetic parameters $K_{s}$ and $n_{s}$ were determined by numerical solution of the inverse task, using the kinetics of accumulation of $\mathrm{HbNO}$ in four experiments of the (I) interaction with $\mathrm{Hb}$ (Table 1 ).

Calculations were carried out at the value of the equilibrium constant $K_{5}=0.5 \times 10^{9} \mathrm{M}^{-1}$, which provides a better match of theory and experiment than $K_{5}=3 \times 10^{10} \mathrm{M}^{-1}$. This is justified, considering the fact that, in the presence of salts, $K_{5}$ decreases, wherein the salt effect increases in the following order: $\mathrm{NaCl}, \mathrm{KCl}$, sodium citrate, sodium phosphate [24]. In our case, the experiments were performed in $0.05 \mathrm{M}$ phosphate buffer, $\mathrm{pH}$ 7.0. Point values (Table 1) satisfactorily describe the experimental data (Figure 3). As seen from Table 1, increasing the concentration of the complex causes value $n_{s}$ to increase and $K_{s}$ to decrease. Apparently, there are various regions of different binding strength on the surface of $\mathrm{Hb}$ for binding of the cation complex. At low concentrations of complex (I) (number 1 in Table 1), its molecules primarily bind with regions, providing a stronger link (large $K_{s}$ ), and while increasing the concentration of $[(\boldsymbol{I})]_{0}$ during adsorption, they begin to participate in other regions on the $\mathrm{Hb}$ surface with lower bond strength. In processing of the experimental data, this leads to a change in the effective values of the parameters: increase of $n_{s}$ and decrease of $K_{s}$.

\subsection{Possible Location of ( $I$ ) on the Surface of Hb. Cation Binding Sites}

It is known that $\mathrm{Hb}$ is composed of four subunits: two $\alpha(\mathrm{A}, \mathrm{C})$ and two $\beta$ (B, D). The $\alpha$ subunit consists of 141 amino acid residues, and the $\beta$ subunit contains 145 residues. The $\alpha$ subunits are in contact with each other and form a narrow entrance of the through-channel. The $\beta$ subunits are in contact with each $\alpha$ subunit, but are not in contact with each other and form a wide entrance of this channel. On the whole, $\mathrm{Hb}$ is a symmetrical macromolecule with a twofold symmetry axis and a channel running through the structure. It is known that the anion binding site, where DPG is bound, is located in this through-channel [11]. In the through-channel, 8 cationic and 3 anionic pairs of amino acids were located [12]; in general it is positively charged and directly enters the channel, which is also positively charged. Therefore, the complexes (I) and (II) can not penetrate to this channel. It has been shown in [12], using the program PyMOL, that the surface area of Hb has a local concentration of both negatively and positively charged amino acids, as well as more or less than the neutral portion of the surface. 
Among various roughnesses on the Hb surface, there are four large cavities (see Figure 4). Two of them (cavities 1) are located in the region of the negatively charged surface from the side of the wide entrance at equal distances $\left(\sim 13 \AA\right.$ ) from the hemes of the A and D subunits. The volume of the cavity 1 is $\sim 17 \AA^{3}$. Two other large cavities (cavities 2) with volumes of $\sim 850 \AA^{3}$ are also negatively charged and are located symmetrically with respect to the cavity 1 at equal distances from the hemes of the A and D subunits (see Figure 4). The negative potential of the cavities 1 and the adjacent surfaces is formed by the negatively charged carboxyl groups of the following amino acids: cavity 1 (subunits A, B, D), by A-Glu23, A-Glu27, A-Glu30, A-Asp47, B-Glu5, B-Glu6, B-Glu120, B-Asp128, D-Glu89, D-Asp93, and the terminal aminoacid D-His145; cavity 1 (subunits C, D, B), by C-Glu23, C-Glu27, C-Glu30, C-Asp47, D-Glu5, D-Glu6, D-Glu120, D-Asp128, B-Glu89, B-Asp93 and the terminal amino acid B-His145. The negative potential of the cavities 2 and the adjacent surfaces is formed by the negatively charged carboxyl groups of the following amino acids: cavity 2 (subunits A, C, D), by A-Asp85 and the terminal amino acid A-Arg141, C-Asp6, D-Glu42, D-Asp46, D-Asp51; cavity 2 (subunits C, A, B), by C-Asp85 and the terminal amino acid C-Arg141, A-Asp6, B-Glu42, B-Asp46, B-Asp51. Most likely, the complex (II) can be located in these cavities and can be bound to the negatively charged functional groups of $\mathrm{Hb}$. Correspondingly, it can be suggested that at least one (II) molecule can be bound in the cavity 1 , and at least three (II) molecules can be bound in the cavity 2. In total, each $\mathrm{Hb}$ molecule can bind at least eight (II) molecules. Taking into account the results of the kinetic modeling [12], which gave approximately 12 (II)-binding sites per $\mathrm{Hb}$ molecule, it can be concluded that there are from 8 to 12 such sites. Figure 4 shows that, in addition to the cavities 1 and 2, there are adjacent surfaces bearing a negative charge. Apparently, they are also involved in the binding of (II). The surfaces in the direct vicinity of the hemes are positively charged, the charge gradually decreasing with increasing distance from the heme. In this study, we had a different situation. The volume of $(\boldsymbol{I})$ is $\sim 375 \AA^{3}$, and only one molecule of $(\boldsymbol{I})$ can fit into the large, negatively charged cavity, i.e., to cavity 2. Moreover, in this case, the binding is stronger: $K_{s}=4.3 \times 10^{7} \mathrm{M}^{-1}$. Therefore, the $(I)$ molecules bind more weakly. The PyMOL program identifies shallow and indistinct regions with mixed charge from a small positive to a negative charge on the surface of the $\beta$-subunit at a distance of approximately $10 \AA$ from the heme. On such areas, the binding of $(\boldsymbol{I})$ probably occurs in this case, starting from a negative area. So $K_{s}$ decreases with increasing concentrations of $(\boldsymbol{I})$.

\section{Conclusion}

The results of this work on the interaction of the complex (I) with Hb fully confirm and complement the findings of [12] of cations binding sites on the Hb surface. The function of these sites in metabolism in general has not yet been established. However, it is clear in the case of NICs. That negative cavities on the surface of $\mathrm{Hb}$ are the pools of NICs. Associated with Hb molecules NICs emit NO slightly $\left(k \sim 10^{-8} s^{-1}\right)$. Hb may carry adsorbed

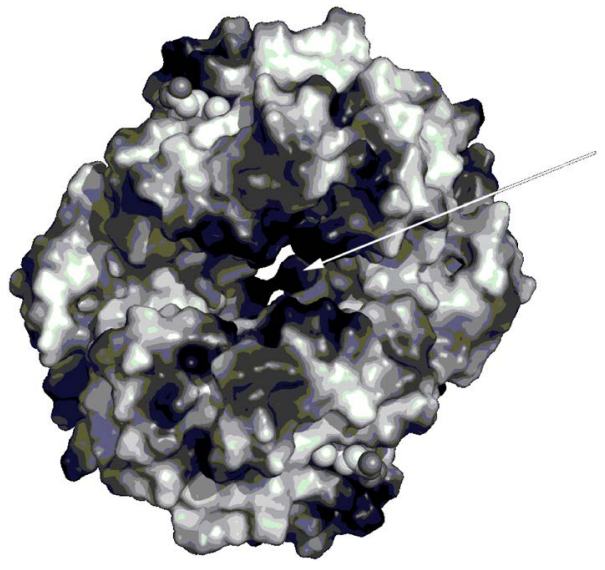

(a)

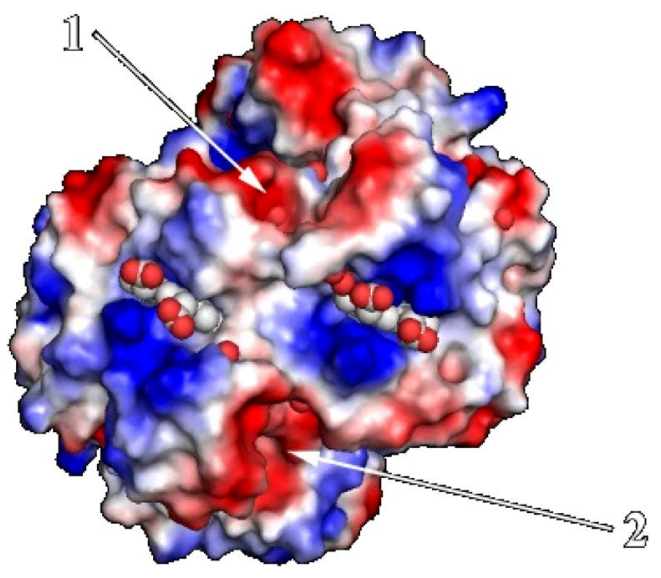

(b)

Figure 4. Analysis of the Hb surface. The regions with a negative surface charge are shown in red (b) or gtey (a), and the regions with a positive surface charge are shown in blue (b) or black (a). The X-ray diffraction data for the bovine Hb molecule [25] are used. (a) The view on to the through-channel (indicated by an arrow); (b) The view onto the cavities 1 and 2. Figure 4 was taken from paper [12]. 
therein NICs to other targets. Since NICs associated with Hb reversibly, under decreasing NICs concentration lose contact with it. We can assume that the binding sites of cations can also be carriers of other metabolites with positively charged functional groups.

\section{Acknowledgements}

This study was financially supported by the RFBR (Grant No. 13-03-00549).

We wish to thank Dr. A.V. Chudinov for the preparation of program of computer processing of absorption spectra by the least square method using program MathCad.

\section{Supplementary Material}

CCDC 680286 contains the supplementary crystallographic data for complex (I)

$\left[\mathrm{Fe}_{2}\left(\mathrm{SC}_{5} \mathrm{H}_{11} \mathrm{NO}_{2}\right)_{2}(\mathrm{NO})_{4}\right] \mathrm{SO}_{4} \cdot 5 \mathrm{H}_{2} \mathrm{O}$.

CCDC 663194 contains the supplementary crystallographic data for complex (II)

$\left[\mathrm{Fe}_{2}\left(\mathrm{~S}_{(}\left(\mathrm{CH}_{2}\right)_{2} \mathrm{NH}_{3}\right)_{2}(\mathrm{NO})_{4}\right] \mathrm{SO}_{4} \cdot 2.5 \mathrm{H}_{2} \mathrm{O}$. These data can be obtained free of charge from Cambridge Crystallographic Data Centre via http://www.ccdc.cam.ac.uk/conts/retrieving.html

\section{References}

[1] Lancaster, J.R. (2010) Metal-Catalyzed Nitric Oxide Nitrozo Interconversions and Biological Signaling. Nitric Oxide: Biology and Chemistry, 22, 13.

[2] Lewandowska, H., Kalinowska, M., Brzoska, K., Wojciuk, K., Wojciuk, G. and Kruszewski, M. (2011) Nitrosyl Iron Complexes-Synthesis, Structure and Biology. Dalton Transactions, 40, 8273-8289. http://dx.doi.org/10.1039/c0dt01244k

[3] Mocellin, S. (2009) Nitric Oxide: Cancer Target or Anticancer Agent? Current Cancer Drug Targets, 9, 214-236. http://dx.doi.org/10.2174/156800909787581015

[4] Wink, D.A. and Mitchell, J.B. (1998) Chemical Biology of Nitric Oxide: Insights into Regulatory, Cytotoxic, and Cytoprotective Mechanisms of Nitric Oxide. Free Radical Biology Medicine, 25, 434-456. http://dx.doi.org/10.1016/S0891-5849(98)00092-6

[5] Morbidelli, L., Donnini, S. and Ziche, M. (2004) Role of Nitric Oxide in Tumor Angiogenesis. Cancer Treatment and Research, 117, 155-167. http://dx.doi.org/10.1007/978-1-4419-8871-3_11

[6] Prostovit, L.M., Adams, M.A., Lash, G.E., Heaton, J.P. and Graham, C.H. (2002) Oxygen-Mediated Regulation of Tumor Cell Invasiveness. Involvement of a Nitric Oxide Signaling Pathway. Journal of Biological Chemistry, 277, 35730-35737. http://dx.doi.org/10.1074/jbc.M204529200

[7] Sanina, N.A. and Aldoshin, S.M. (2011) Structure and Properties of Iron Nitrosyl Complexes with Functionalized Sulfur-Containing Ligands. Russian Chemical Bulletin, International Edition, 60, 1223-1251. http://dx.doi.org/10.1007/s11172-011-0192-x

[8] Sanina, N.A., Syrtsova, L.A., Shkondina, N.I., Rudneva, T.N., Malkova, E.S., Bazanov, T.A., Kotel'nikov, A.I. and Aldoshin, S.M. (2007) Reaction of Sulfur-Nitrosyl Iron Complexes of “g = 2.03” Family with Hemoglobin (Hb): Kinetics of Hb-NO Formation in Aqueous Solutions. Nitric Oxide: Biology and Chemistry, 16, 181-188. http://dx.doi.org/10.1016/j.niox.2006.10.005

[9] Sanina, N.A., Syrtsova, L.A., Shkondina, N.I., Malkova, E.S., Kotelnikov, A.I. and Aldoshin, S.M. (2007) Hemoglobin-Stabilized Tetranitrosyl Binuclear Iron Complex with Pyridine-2-yl in Aqueus Solutions. Russian Chemical Bulletin, International Edition, 56, 761-766. http://dx.doi.org/10.1007/s11172-007-0114-0

[10] Roudneva, T.N., Syrtsova, L.A., Sanina, N.A., Shkondina, N.I., Kotelnikov, A.I. and Aldoshin, S.M. (2010) Formation of Iron Nitrosyl Complexes of Ferri- and Ferrocytochrome C at Its Interaction with Nitrosyl Iron Complex Cysaconite. Nitric Oxide: Biology and Chemistry, 22, 546.

[11] Arnone, A. (1972) X-Ray Diffraction Study of Binding of 2,3-Diphosphoglycerate to Human Deoxyhaemoglobin. Nature, 237, 146-149. http://dx.doi.org/10.1038/237146a0

[12] Sanina, N.A., Syrtsova, L.A., Psikha, B.L., Tukhvatullin, I.A., Shkondina, N.I., Rudneva, T.N., Kotel’nikov, A.I. and Aldoshin, S.M. (2012) Revealing of the Cation-Binding Sites on the Surface of Hemoglobin in Its Reaction with the

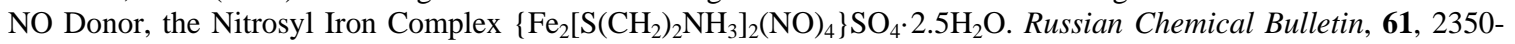
2355. http://dx.doi.org/10.1007/s11172-012-0330-0

[13] Sanina, N.A., Lysenko, K.A., Zhukova, O.S., Roudneva, T.N., Emel'yanova, N.S. and Aldoshin, S.M. (2011) WaterSoluble Binuclear Nitrosyl Iron Complexes with Natural Aliphatic Thiolyls Possessing Cytotoxic, Apoptotic and NO 
Donor Activity. Patent No. US 8, 067, 628 B2.

[14] Roudneva, T.N., Sanina, N.A., Lyssenko, K.A., Aldoshin, S.M., Antipin, M.Y. and Ovanesyan, N.S. (2009) Synthesis and Structure of a Water-Soluble Nitrosyl Iron Complex with Cysteamine Ligand. Mendeleev Communications, 19, 253-255. http://dx.doi.org/10.1016/j.mencom.2009.09.006

[15] Sanina, N.A., Serebryakova, L.I., Shul'zhenko, N.S., Pisarenko, O.I., Roudeva, T.N. and Aldosin, S.M. (2012) Application of Iron Binuclear Complex Sulphur-Nitrosyl Complex of the Canionic Type as a Vasodilative Drug. Patent No. RU No 2460531 C1.

[16] De Lano, W.L. (2002) The PyMOL Molecular Graphics System. Version 0.99rc6 Schrödinger, LLC, De Lano Scientific, San Carlos.

[17] Perutz, M.F., Fermi, G., Poyart, C., Pagnier, J. and Kister, J. (1993) A Novel Allosteric Mechanism in Haemoglobin. Structure of Bovine Deoxyhaemoglobin, Absence of Specific Chloride-Binding Sites and Origin of the ChlorideLinked Bohr Effect in Bovine and Human Haemoglobin. Journal of Molecular Biology, 233, 536-545. http://dx.doi.org/10.1006/jmbi.1993.1530

[18] Bernstein, F.C., Koetzle, T.F., Williams, G.J.B., Meyer Jr., E.F., Brice, M.D., Rodgers, J.R., Kennard, O., Shimanouchi, T. and Tasumi, M. (1977) The Protein Data Bank: A Computer-Based Archival File for Macromolecular Structures. Journal of Molecular Biology, 112, 535-542. http://dx.doi.org/10.1016/S0022-2836(77)80200-3

[19] Miles, A.M., Wink, D.A., Cook, J.C. and Grisham, M.B. (1996) Determination of Nitric Oxide Using Fluorescence Spectroscopy. In: Packer, L., Ed., Methods in Enzymology V, Part A, Academic Press, New York, 105-121.

[20] Cassoly, R. and Gibson, Q.H. (1975) Conformation, Co-Operativity and Ligand Binding in Human Hemoglobin. Journal of Molecular Biology, 91, 301-313. http://dx.doi.org/10.1016/0022-2836(75)90382-4

[21] Antonini, E. and Brunori, M. (1971) Hemoglobin and Myoglobin in the Reactions with Ligands. In: Neuberger, A. and Tatum, E.L., Eds., North-Holland Research Monographs. Frontiers of Biology, Vol. 21, North-Holland Publishing Company, Amsterdam and London, 276.

[22] Syrtsova, L.A., Sanina, N.A., Lyssenko, K.A., Kabachkov, E.N., Psikha, B.L., Shkondina, N.I., Pokidova, O.V., Kotelnikov, A.I. and Aldoshin, S.M. (2014) Reversible Dissociation and Ligand-Glutathione Exchange Reaction in Binuclear Cationic Tetranitrosyl Iron Complex with Penicillamine. Bioinorganic Chemistry and Applications, 2014, Article ID: 641407. http://dx.doi.org/10.1155/2014/641407

[23] Sanina, N.A. Syrtsova, L.A., Chudinova, E.S., Shkondina, N.I., Rudneva, T.N., Kotelrnikov, A.I. and Aldoshin, S.M. (2009) Regularities in the Stabilization by Hemoglobin of Binuclear Iron Complexes $\left[\mathrm{Fe}_{2}(\mu-\mathrm{N}-\mathrm{C}-\mathrm{SR})_{2}(\mathrm{NO})_{4}\right]$ Containing Benzimidazolyl and Benzothiazolylthiol Ligands. Russian Chemical Bulletin, 58, 566-571.

[24] Haurowitz, F. and Hardin, R. (1954) Respiratory Proteins. In: Neurath, H. and Bailey, K., Eds., The Proteins, Academic Press, New York, 279-344.

[25] Perutz, M.F., Shih, D.T. and Williamson, D. (1994) The Chloride Effect in Human Hemoglobin: A New Kind of Allosteric Mechanism. Journal of Molecular Biology, 239, 555-560. http://dx.doi.org/10.1006/jmbi.1994.1394

\section{Abbreviations}

(I) complex $\left[\mathrm{Fe}_{2}\left(\mathrm{SC}_{5} \mathrm{H}_{11} \mathrm{NO}_{2}\right)_{2}(\mathrm{NO})_{4}\right] \mathrm{SO}_{4} \cdot 5 \mathrm{H}_{2} \mathrm{O}$

(II) complex $\left[\mathrm{Fe}_{2}\left(\mathrm{~S}\left(\mathrm{CH}_{2}\right)_{2} \mathrm{NH}_{3}\right)_{2}(\mathrm{NO})_{4}\right] \mathrm{SO}_{4} \cdot 2.5 \mathrm{H}_{2} \mathrm{O}$

NIC nitrosyl iron complex

$\mathrm{Hb}$ deoxyhemoglobin 